\title{
Power Efficient Frequency Scaled and Thermal- Aware Control Unit Design on FPGA
}

\author{
Keshav Kumar, Shabeer Ahmad, Bishwajeet Pandey, Amit K Pandit, Deepa Singh, D M Akbar \\ Hussain
}

\begin{abstract}
These works describe the implementation of a control unit which is an important part of Central Processing Unit (CPU) with the Field Programmable Gate Array (FPGA). In this work a frequency scaled and thermal aware energy-efficient control unit is designed with the help of 28 nanometer (nm) technology based FPGA. Frequency varies from $100 \mathrm{MHz}$ to $5 \mathrm{GHz}$ and the rise in frequency also gives rise in power consumption of control unit with FPGA. The thermal properties of FPGA also increase with increment in frequency. This whole experiment is done on Xilinx 14.1 ISE Design Suit and it is observed that lower the frequency, lower will be the power consumption of FPGA.
\end{abstract}

Keywords: FPGA, Control Unit, Frequency, Thermal Properties

\section{INTRODUCTION}

Today's era is receiving new attention towards green communication [1]. The demand of the world towards technologies of energy-efficient communication and devices is increasing rapidly [2]. This work gives a ray of light on designing an energy-efficient control unit with the help of 28nm Artix-7 FPGA. In this working frequency of operation of the control unit is scaled from $100 \mathrm{MHz}$ to $5 \mathrm{GHz}$. The different set of frequencies for which power consumption is analysed is shown in Fig. 1.

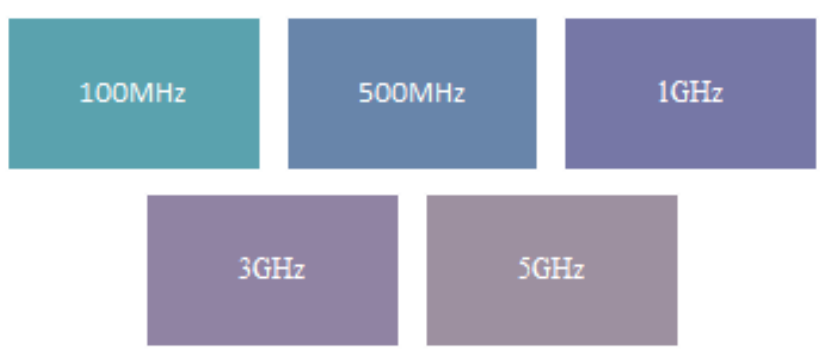

Figure 1. A different set of frequencies for the operation of the control unit.

A control unit is a circuitry component that governs the operation within the computer's processor [3]. It gives direction to the computer's logic unit, memory, input and output devices on how to respond to the instructions sent by

Revised Manuscript Received on July 18, 2019.

Keshav Kumar, Chitkara University Institute of Engineering \& Technology, Chitkara University, Punjab, India (email: keshav.kumar@chitkara.edu.in)

Shabeer Ahmad, Gran Sasso Science Institute, L'Aquila, Italy (email: shabeer.ahmad@gssi.it)

Bishwajeet Pandey, Center of Energy Excellence, Gyancity Research Lab, Motihari, Bihar, India (email: gyancity@gyancity.com)

Amit K Pandit, The Shri Mata Vaishno Devi University, Katra, Jammu and Kashmir, India (email: amit.pandit@smvdu.ac.in)

Deepa Singh, ABV-IIITM, Gwalior, India (email: deepa@iiitm.ac.in)

D M Akbar Hussain, Department of Energy Technology, Aalborg University, Esbjerg, Denmark (email: akh@et.aau.dk) the program to these devices [4]. The block diagram of the control unit is shown in Fig. 2.

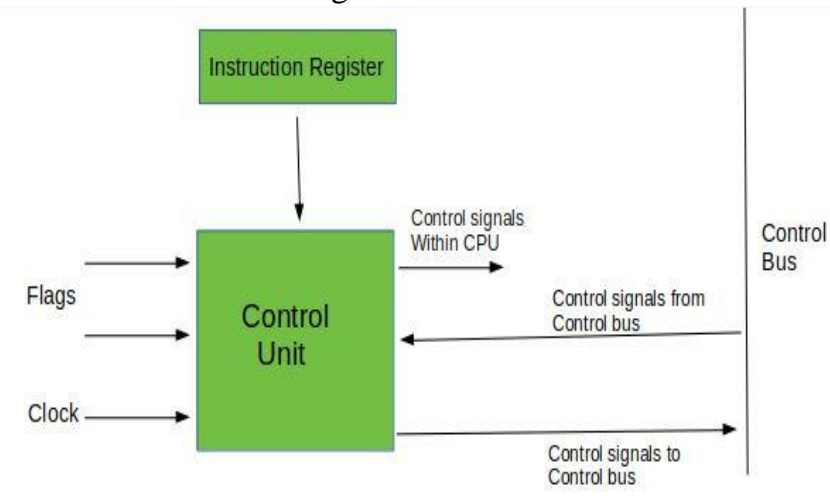

Figure 2. Block diagram of the control unit [4].

\section{RELATED WORK}

In [5] the authors used FPGA to generate a true random number by inducing meta-stability and bi-stable circuit. In [6] developed photovoltaic modules for real-time simulation using FPGA. In [7] researchers implemented the Arithmetic Logic Unit (ALU) design on FPGA by changing frequency values. In [8] researchers used Virtex-6 FPGA to design four-bit unsigned up counter by enabling clock and with an asynchronous clear. In [9] authors interfaced Random Access Memory (ROM) design on Virtex-6 FPGA.

\section{EXPERIMENTAL SETUP}

This experiment is performed on Xilinx 14.1 ISE simulator and the code of control unit is written in Verilog Hardware Description Language (HDL). Power analysis of control unit is done with $\mathrm{X}$ Power Analyser tool. The schematic of the control unit obtained from Xilinx simulator is shown in Fig. 3. 


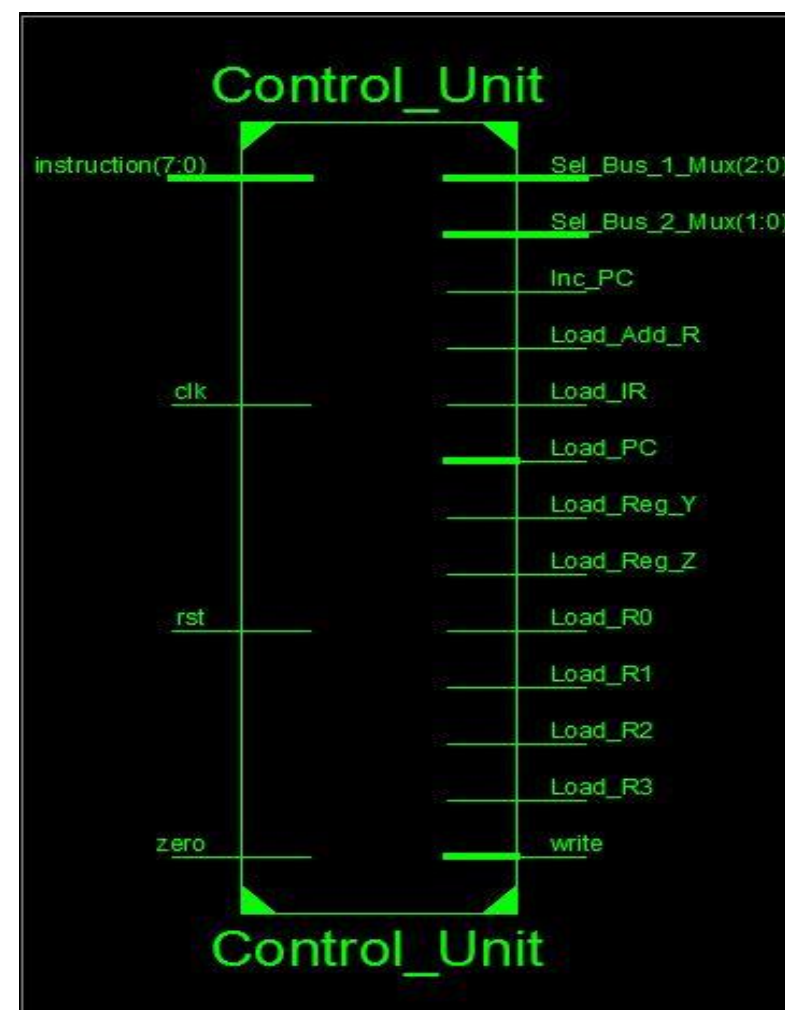

Figure 3. Schematic of the control unit.

\section{POWER ANALYSIS}

4.1 Power Analysis for frequency 100MHz.

When the frequency is $100 \mathrm{MHz}$, there is no consumption of logic and signal power of FPGA. Total power consumption is $0.048 \mathrm{~W}$ which constitutes $0.001 \mathrm{~W}$ clock power, $0.005 \mathrm{~W}$ input/output (I/O) power and $0.042 \mathrm{~W}$ leakage power. Fig. 4 represents the power consumption graph of Artix-7 FPGA at $100 \mathrm{MHz}$ frequency.

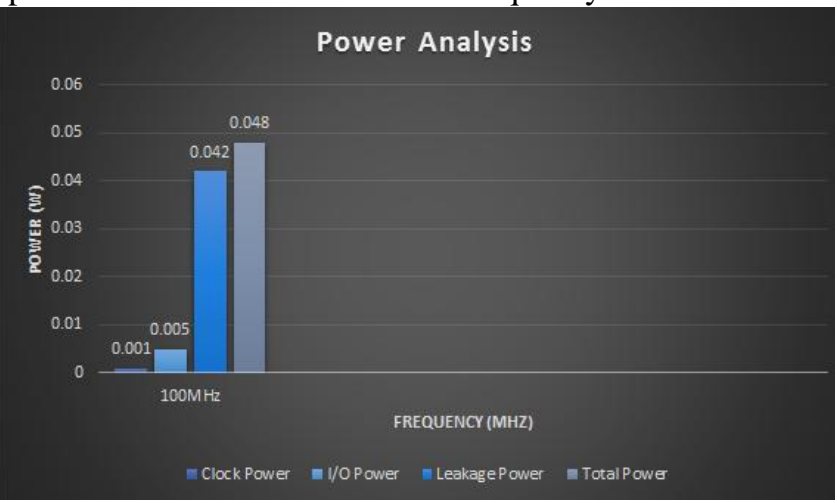

Fig. 4. Power Analysis for frequency 100MHz.

\subsection{Power Analysis for frequency $500 \mathrm{MHz}$.}

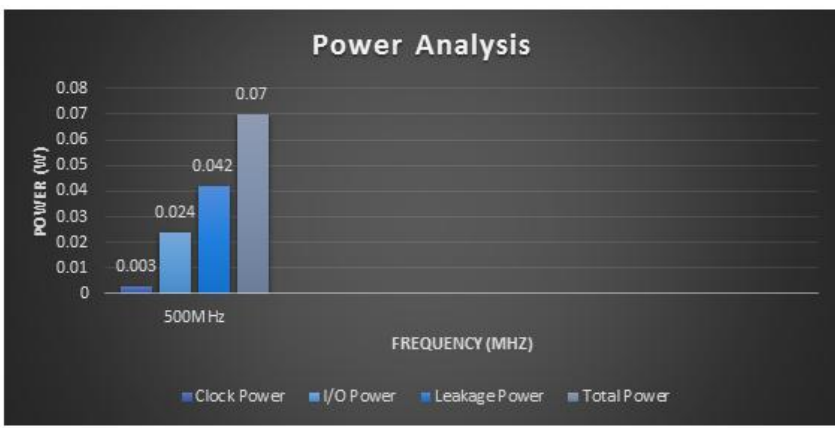

Fig. 5 Power Analysis for frequency 500MHz.

\subsection{Power Analysis for frequency $1 \mathrm{GHz}$.}

At $1 \mathrm{GHz}$ of frequency, logic power is $0.000 \mathrm{~W}$. Total power consumption of $0.097 \mathrm{~W}$ comprises of clock power which is $0.005 \mathrm{~W}$, signal power which is $0.001 \mathrm{~W}, \mathrm{I} / \mathrm{O}$ power which is $0.048 \mathrm{~W}$ and leakage power which is $0.043 \mathrm{~W}$, which can be seen in Fig. 6.

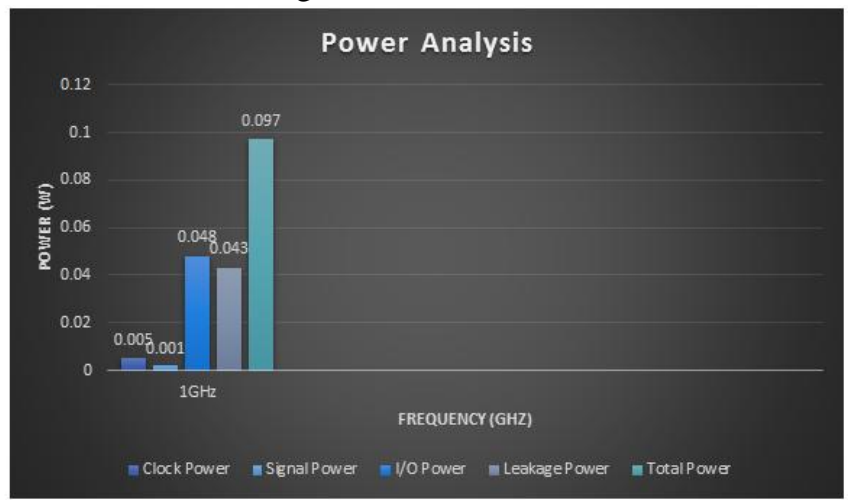

Figure 6. Power Analysis for frequency $1 \mathrm{GHz}$.

\subsection{Power Analysis for frequency $3 \mathrm{GHz}$.}

When the frequency is $3 \mathrm{GHz}$ then all the on chips power of FPGA contributes to total power consumption. At $3 \mathrm{GHz}$ of frequency, clock power is $0.016 \mathrm{~W}$, logic power is 0.001 , and the signal power is $0.002 \mathrm{~W}, \mathrm{I} / \mathrm{O}$ power $0.144 \mathrm{~W}$ and leakage power $0.043 \mathrm{~W}$. Power analysis at $3 \mathrm{GHz}$ frequency is shown in Fig. 7.

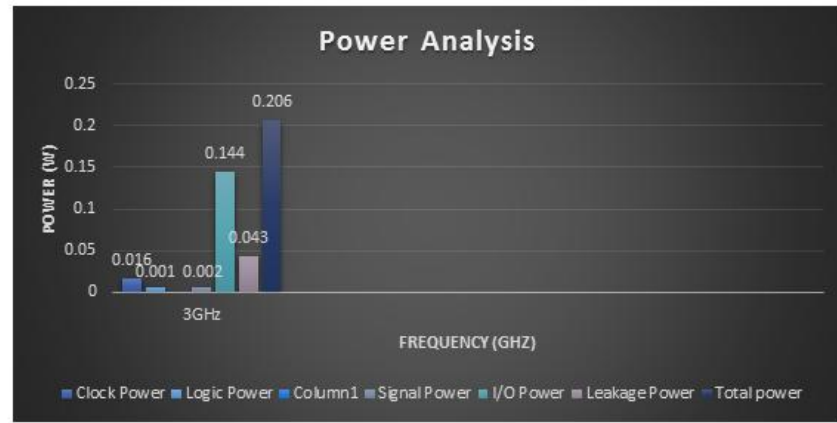

Figure 7. Power Analysis for frequency $3 \mathrm{GHz}$.

4.5 Power Analysis for frequency $5 \mathrm{GHz}$

At $5 \mathrm{GHz}$ of frequency, clock power, logic power, signal power, I/O power and leakage power are $0.026 \mathrm{~W}, 0.001 \mathrm{~W}$, $0.004 \mathrm{~W}, 0.241 \mathrm{~W}$ and $0.043 \mathrm{~W}$ respectively. All this on chips power contributes to total power consumption of $0.315 \mathrm{~W}$. Power analysis graph is described in Fig. 8.

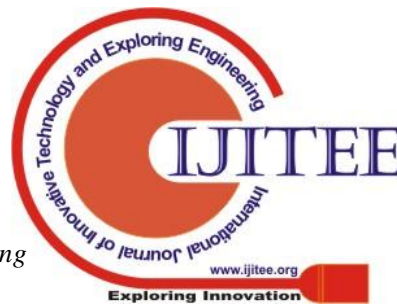




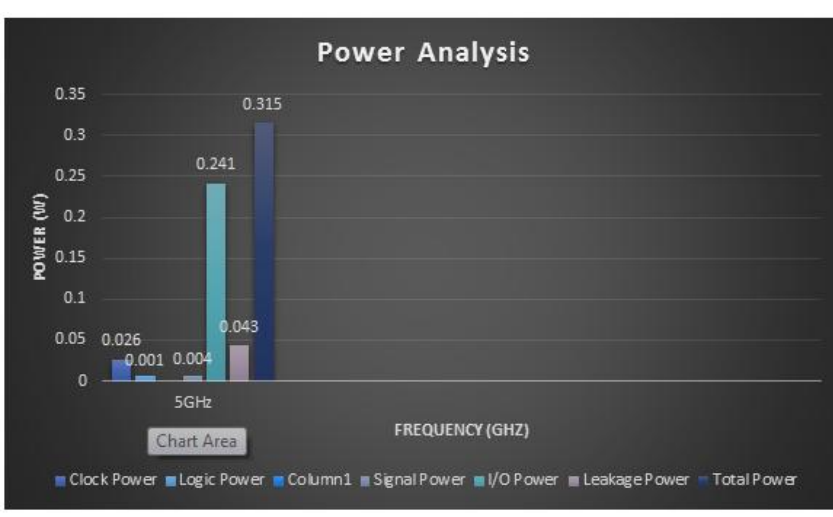

Figure 8. Power Analysis for frequency 5GHz.

\section{THERMAL CONDITIONS FOR FREQUENCIES 100MHZ, 500MHZ, 1GHZ, 3GHZ AND 5GHZ}

Thermal condition of a device plays an important role in device power consumption. The three major parameters which govern key role in FPGA power consumption are as follows:

A. Effective Thermal Resistance to Air $\left(\Theta \mathrm{JA}\left({ }^{\circ} \mathrm{C} / \mathrm{W}\right)\right)$ - It is also known as Theta-JA and TJA.

B. Maximum Ambient Temperature $\left({ }^{\circ} \mathrm{C}\right)$.

C. Junction Temperature $\left({ }^{\circ} \mathrm{C}\right)$.

The effective thermal resistance to air $\left(\Theta \mathrm{JA}\left({ }^{\circ} \mathrm{C} / \mathrm{W}\right)\right)$ is the same at all values of frequencies that is 3.3 ( $\Theta \mathrm{JA}$ $\left.\left({ }^{\circ} \mathrm{C} / \mathrm{W}\right)\right)$. The maximum ambient temperature of FPGA decreases with increase in frequency and junction temperature of FPGA increases with increase in frequency. Table 1. Represents the thermal properties of Artix-7 FPGA.

\begin{tabular}{|c|c|c|c|c|c|}
\hline $\begin{array}{c}\text { Thermal } \\
\text { Properties }\end{array}$ & $100 \mathrm{MHz}$ & $500 \mathrm{MHz}$ & $1 \mathrm{GHz}$ & $3 \mathrm{Ghz}$ & $5 \mathrm{GHz}$ \\
\hline $\begin{array}{c}\text { Effective } \\
\text { Thermal } \\
\text { Resistance to } \\
\text { Air }(\Theta \mathrm{AJ} \\
\left.\left({ }^{\circ} \mathrm{C} / \mathrm{W}\right)\right)\end{array}$ & 3.3 & 3.3 & 3.3 & 3.3 & 3.3 \\
\hline $\begin{array}{c}\text { Maximum } \\
\text { Ambient } \\
\text { Temperature } \\
\left({ }^{\circ} \mathrm{C}\right) .\end{array}$ & 84.8 & 84.8 & 84.7 & 84.3 & 84.0 \\
\hline $\begin{array}{c}\text { Junction } \\
\text { Temperature } \\
\left({ }^{\circ} \mathrm{C}\right) .\end{array}$ & 25.2 & 25.2 & 25.3 & 25.7 & 26.0 \\
\hline
\end{tabular}

Table 1. Thermal Properties of Artix-7 FPGA.

\section{RESULT ANALYSIS}

The power consumption of control unit circuitry interfaced with Artix-7 FPGA increases with increase in frequency. The total power consumption for $100 \mathrm{MHz}$, $500 \mathrm{MHz}, 1 \mathrm{GHz}, 3 \mathrm{GHz}$, and $5 \mathrm{GHz}$ is as $0.048 \mathrm{~W}, 0.070 \mathrm{~W}$, $0.097 \mathrm{~W}, 0.206 \mathrm{~W}$ and $0.315 \mathrm{~W}$ respectively. There is an increment of $45.83 \%$ of total power consumption from $100 \mathrm{MHz}$ frequency to $500 \mathrm{MHz}$ frequency, also there is an increment of $102.08 \%, 329.17 \%$ and $556.25 \%$ of total power consumption, when frequency increases from $100 \mathrm{MHz}$ to $1 \mathrm{GHz}, 3 \mathrm{GHz}$ and $5 \mathrm{GHz}$ frequency. Fig. 9 describes the comparison of the total power consumption of Artix-7 FPGA for different values of frequencies.

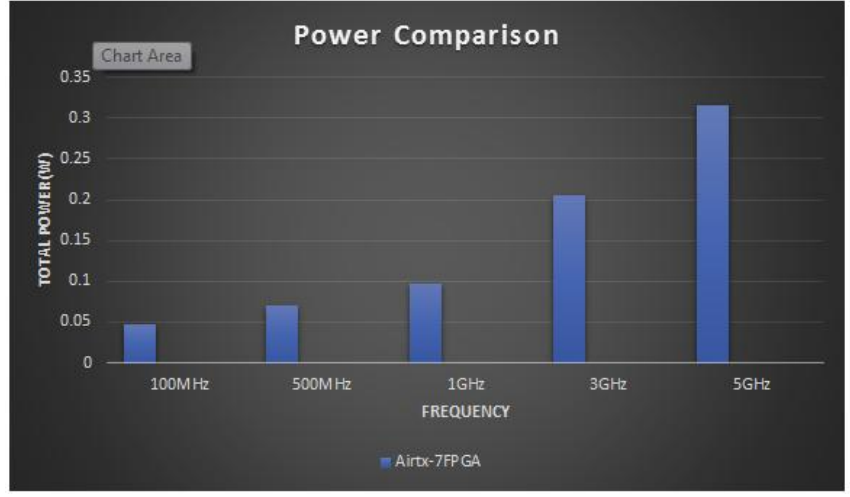

Figure 9. Total Power comparison.

\section{CONCLUSION}

In this experiment control unit is implemented on Artix-7 FPGA and it is observed that as the value of frequency increases, there is also increased in power consumption. For low power consumption, the frequency must be as low as possible. In this experiment it is found that at $100 \mathrm{MHz}$ frequency power consumption is lowest, hence it can be concluded that control unit interfacing with Artix-7 FPGA is the most power-efficient at $100 \mathrm{MHz}$ frequency.

\section{FUTURE SCOPE}

Unlike Artix-7 FPGA, researchers can use other FPGAs also like Spartan family FPGA, Virtex family FPGA, Cyclone FPGA etc. to analyse the power consumption of control unit. Not only control unit researchers can implement other circuits also with FPGA to promote a step towards green communication.

\section{REFERENCES}

1. Vereecken, Willem, Ward Van Heddeghem, Didier Colle, Mario Pickavet, and Piet Demeester. "Overall ICT footprint and green communication technologies." In 2010 4th International Symposium on Communications, Control and Signal Processing (ISCCSP), pp. 1-6. IEEE, 2010.

2. https://www.igi-global.com/dictionary/key-issues-andresearch-directions-in-green-wireless-networking/43606 (17/06/2019).

3. https://www.computerhope.com/jargon/c/contunit.htm $(19 / 6 / 16)$

4. https://www.geeksforgeeks.org/computer-organizationcontrol-unit-and-design/ (19/6/16).

5. Majzoobi, Mehrdad, Farinaz Koushanfar, and Srinivas Devadas. "FPGA-based true random number generation using circuit metastability with adaptive feedback control." In International Workshop on Cryptographic Hardware and Embedded Systems, pp. 17-32. Springer, Berlin, Heidelberg, 2011.

6. E. Koutroulis, K. Kalaitzakis, and V. Tzitzilonis "Development of an FPGA-based system for real-time simulation of photovoltaic modules." Microelectronics journal 40, no. 7 (2009): 1094-1102.

7. Pandey, Bishwajeet, and Manisha Pattanaik. "Clock gating aware low power ALU design and implementation on FPGA." International Journal of Future Computer and

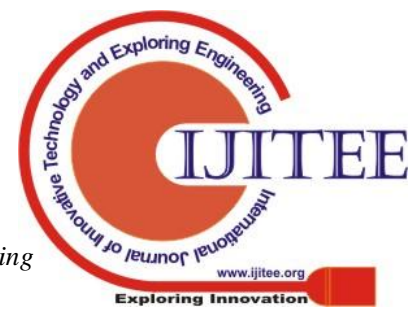


Communication2, no. 5 (2013): 461.

8. Pandey, Bishwajeet, and Manisha Pattanaik. "Low power VLSI circuit design with efficient HDL coding." In 2013 International Conference on Communication Systems and Network Technologies, pp. 698-700. IEEE, 2013.

9. Bansal, Meenakshi, Neha Bansal, Rishita Saini, Bishwajeet Pandey, Lakshay Kalra, and DM Akbar Hussain. "SSTL I/O Standard based environment friendly energyl efficient ROM design on FPGA." In 3rd International Symposium on Environmental Friendly Energies and Applications (EFEA), pp. 1-6. IEEE, 2014. 